\title{
A Breath of Fresh Air into Iranian English Textbooks Evaluation of English Textbook "Vision2" for Iranian High School Students from Teachers' Perspectives
}

\author{
Boshra Mallahi ${ }^{1} \&$ Shahram Afraz ${ }^{2}$ \\ ${ }^{1} \mathrm{MA}$ in TEFL, Qeshm International Branch, Islamic Azad University, Qeshm, Iran \\ ${ }^{2}$ Department of English Language, Qeshm Branch, Islamic Azad University, Qeshm, Iran \\ Correspondence: Boshra Mallahi, MA in TEFL, Qeshm International Branch, Islamic Azad University, Qeshm, \\ Iran.
}

Received: November 24, 2018; Accepted: December 8, 2018; Published: January 1, 2019

\begin{abstract}
The Purpose of this study was to investigate the appropriateness of newly developed Iranian high school English textbook "Vision2" from teachers" points of view. 25 male and female high school English teachers were randomly selected from Hormozgan province, Iran to participate in the study. The evaluation of textbook was conducted quantitatively through a 3-points Likert scale checklist which was proposed by Dr. Montasser Mohamed AbdelWahab (2013). The data was subjected to analysis through descriptive statistics. Findings indicated that although the book has some strong sides, teachers pointed to major weaknesses in textbook in terms of lack of glossary list, shortage of time to cover the stated objectives and a need to recycling the newly learned vocabularies in subsequent lessons. In the light of these findings, the researcher reported some recommendations to address the slight drawbacks of the English language textbook for $11^{\text {th }}$ grade. The findings of the study would be useful for teachers and material developers.
\end{abstract}

Keywords: Evaluation, English Textbook, Vision2

\section{Introduction}

As stated by Zohrabi, Sabouri, and Kheradmand (2014),"textbooks are one of the elements that may promote or discourage learners depending on their materials. They are a kind of support for both teachers and learners. Textbooks provide students a kind of consistency "(p.95). Textbooks are essential tools in improving learning and teaching and helping teachers to carry out their responsibility satisfactory. Since the major users of the textbooks are the students and teachers, their opinions toward textbooks should be collected and analyzed.

Teachers have the responsibility of evaluating textbooks, so the evaluation of teaching materials is an integral part of a teacher's work. , the main focus of this research is to evaluate the teachers' viewpoints regarding the new textbook "Vision2". The researcher tried to find out high school teachers ' perceptions towards the new textbook. Taking these points into consideration, the present study probed into finding out teachers' perceptions of the Iranian high school English textbook "Vision2"(Ansari \&Babaii (2002). The aim of this study is to evaluate the new version of Iranian EFL high school textbook "vision2" from teachers' perspectives. This study will evaluate the English textbook through Dr. Montasser Mohamed AbdelWahab's evaluation checklist. His checklist consists of four main criteria including: 1) Physical and utilitarian attributes 2) efficient outlay of objectives and supplementary materials 3) learning teaching content 4) language skills.

\subsection{Research Hypothesis}

1- "Vision2" is not appropriate for Iranian high school students in terms of physical and utilitarian attributes.

2- "Vision2" is not appropriate for Iranian high school students in terms of efficient outlay of objectives and supplementary materials.

3- "Vision2" is not appropriate for Iranian high school students in terms of learning-teaching content.

4- "Vision2" is not appropriate for Iranian high school students in terms of language skills. 


\section{Methodology}

\subsection{Participants}

The participants included 25 experienced English teachers randomly selected from high schools in different districts of Hormozgan province, Iran. They were asked to fill in the questionnaire prepared by Dr. Montasser Mohamed AbdelWahab carefully and honestly and issue their opinions about the textbook. The respondents were asked to put a tick mark in the column of their choice.

\subsection{Materials}

The English textbook titled "Vision2" evaluated for this study. "Vision 2" is a new textbook which is written by Dr. Ali Moghaddam, Dr. Kheirabad, Rahimi, and Davari (2017). In order to attain the aim of the study, the textbook includes work book, student book, audio CD and teacher's guide.

\subsection{Instruments}

Survey questionnaire was used to know teachers' perspectives on the new English textbook for eleventh grade of high schools in Hormozgan, Iran. An electronic questionnaire adopted from Dr. Montasser Mohamed AbdelWahab textbook evaluation checklist was used. His checklist consists of four main criteria including:1) Physical and utilitarian attributes2) efficient outlay of objectives and supplementary materials3) learning teaching content 4)language skills.

The respondents were asked to put only a tick mark in the column of their choice that represents their perceptions. In this study, 3points Likert scale (poor, satisfactory, good) was utilized.

\subsection{Procedure}

The data gathered through a checklist adopted from Dr. Montasser Mohamed AbdelWahab's evaluation checklist distributed among 25 experienced English teachers randomly selected from different districts of Hormozgan province, Iran.

\subsection{Data Collection}

In order to evaluate the textbook from teachers' viewpoints, data were collected at the end of the educational year. 25 high school English teachers from different districts of Hormozgan province required to complete the questionnaires to reveal their perceptions of new English textbook they used in their classrooms. For data collection a closed-ended questionnaire proposed by Dr. Montasser Mohamed AbdelWahab was distributed to the participants. . Finally, to investigate the results, descriptive statistics were used.

\subsection{Data Analysis}

The data obtained from questionnaires quantitatively analyzed in order to seek overall perceptions of 11 th grade Iranian teachers of English toward English textbooks. The statistical package for science (SPSS) is used for data analysis which included standard deviation, mean, percentage and frequency.

\section{Results}

\subsection{Revisiting the First Research Question}

The first research question was "Is Vision2 appropriate for Iranian high school students in terms of physical and utilitarian attributes?"

The descriptive statistics related to physical and utilitarian Attributes are provided in Table1.

Table 1. The Results of Checklist from the physical and utilitarian attributes

\begin{tabular}{llll|ll|ll}
\hline Textbook evaluation scales & 0 & & 1 & & 2 & \\
\hline General appearance & $\mathrm{N}$ & $\%$ & $\mathrm{~N}$ & $\%$ & $\mathrm{~N}$ & $\%$ \\
Item 1 & 14 & 56 & 7 & 28 & 4 & 16 \\
Item 2 & 2 & 8 & 7 & 28 & 16 & 64 \\
Item 3 & 2 & 8 & 17 & 68 & 6 & 24 \\
Layout and design & $\mathrm{N}$ & $\%$ & $\mathrm{~N}$ & $\%$ & $\mathrm{~N}$ & $\%$ \\
Item 4 & 18 & 72 & 4 & 16 & 3 & 12 \\
Item 5 & 2 & 8 & 8 & 32 & 15 & 60 \\
Item 6 & 10 & 40 & 11 & 44 & 4 & 16 \\
Visuals & $\mathrm{N}$ & $\%$ & $\mathrm{~N}$ & $\%$ & $\mathrm{~N}$ & $\%$ \\
Item 7 & 6 & 24 & 14 & 56 & 5 & 20 \\
\hline
\end{tabular}

$0=$ Poor; $1=$ Satisfactory; $2=$ Good 
As shown in table $1,56 \%$ of teachers stated that the outside cover is not informative and attractive, while $28 \%$ believed that the design of book is satisfactory.(Item 1). The second item that asks about the appropriateness of the font size and type of the textbook, confirmed positively by $64 \%$ of the participants, and $28 \%$ were satisfied with font size and type of the book (Item 2). Around $68 \%$ of the teachers gave satisfactory responses to item three (Item 3). For item four, $72 \%$ of teachers believed that there is not a detailed overview of the function and structures in each unit (Item 4). 60\% of the participants stated their agreement in this aspect, which indicates that there is appropriate overview of vocabulary in the book, but $8 \%$ disagreed with this issue (Item 5). Some teachers about $40 \%$ believed that there are mistakes in the book (Item 6). For the last item in this domain, $56 \%$ of teachers were satisfied with visuals ( Item 7).

\subsection{Revisiting the Second Research Question}

The second research question was" Is Vision2 appropriate for Iranian high school students in terms of efficient outlay of objectives and supplementary materials?"

Table 2. The Results of Checklist from the efficient outlay of objectives and supplementary materials

\begin{tabular}{llll|ll|ll}
\hline Textbook evaluation scales & 0 & & 1 & & 2 & \\
\hline Book objectives & $\mathrm{N}$ & $\%$ & $\mathrm{~N}$ & $\%$ & $\mathrm{~N}$ & $\%$ \\
Item 8 & 17 & 68 & 6 & 24 & 2 & 8 \\
Item 9 & 8 & 32 & 2 & 8 & 15 & 60 \\
Teaching aids & $\mathrm{N}$ & $\%$ & $\mathrm{~N}$ & $\%$ & $\mathrm{~N}$ & $\%$ \\
Item 10 & 1 & 4 & 10 & 40 & 14 & 56 \\
Item 11 & 5 & 20 & 6 & 24 & 14 & 56 \\
Item 12 & 16 & 64 & 7 & 28 & 2 & 8 \\
\hline
\end{tabular}

$0=$ Poor; $1=$ Satisfactory; $2=$

The first item in this domain is about the relevance of objectives to learners' need and interest.56\% of the teachers stated that they are satisfied in this aspect, but $24 \%$ disagreed with this issue (Item 8 ). The second item in this part which is about balance between four main skills, listening, speaking, reading and writing, were answered by $68 \%$ of the teachers in negative way, while $24 \%$ were satisfied with this item (Item 9). $60 \%$ of teachers believed that activities allow students to talk more than teachers but $32 \%$ declared they are not satisfied with this item (Item10). $56 \%$ of teachers admitted that the activities and exercises introduce the main principle of CLT (Item 11). In the last case of this section, $64 \%$ of the participants stated that the activities used in the book do not enable the learners to use English outside the classroom (Item 12).

\subsection{Revisiting the Third Research Question}

The third research question was "Is Vision2 appropriate for Iranian high school students in terms of learningteaching content?"

\section{Subject and Content}

Item 13-15 evaluate the textbook's subject and content. The results related to subject and content are presented in table 3.

Table 3. The Results of Checklist from the Subject and content

\begin{tabular}{llll|ll|ll}
\hline Textbook evaluation scales & 0 & & 1 & & 2 & \\
\hline Subject and Content & $\mathrm{N}$ & $\%$ & $\mathrm{~N}$ & $\%$ & $\mathrm{~N}$ & $\%$ \\
Item 13 & 21 & 84 & 2 & 8 & 2 & 8 \\
Item 14 & 8 & 32 & 14 & 56 & 3 & 12 \\
Item 15 & 4 & 16 & 17 & 68 & 4 & 16 \\
\hline
\end{tabular}

$0=$ Poor; $1=$ Satisfactory; $2=\overline{\text { Good }}$

As indicated in table 3, 84\% of the participants didn't support the statement that the book contains fun elements (Item 13). About $48 \%$ of teachers stated that the subject and content of this book is not interesting, challenging and motivating, while $44 \%$ of participants were satisfied with this item (Item 14). $68 \%$ of teachers were satisfied with 
the statement that the topics provide a list of new or difficult words, while $16 \%$ of them rejected this item, and the rest $16 \%$ agreed this statement (Item 15).

Items 16-19 evaluate the textbook's exercises.

Table 4. The Results of Checklist from the exercises

\begin{tabular}{llllllll}
\hline Textbook evaluation scales & 0 & & 1 & & 2 & \\
\hline Exercises & $\mathrm{N}$ & $\%$ & $\mathrm{~N}$ & $\%$ & $\mathrm{~N}$ & $\%$ \\
Item 16 & 4 & 16 & 8 & 32 & 13 & 52 \\
Item 17 & 6 & 24 & 12 & 48 & 7 & 28 \\
Item 18 & 7 & 28 & 8 & 32 & 10 & 40 \\
Item 19 & 8 & 32 & 13 & 52 & 4 & 16 \\
\hline
\end{tabular}

$0=$ Poor; $1=$ Satisfactory; $2=\overline{\text { Good }}$

As it is shown in table $4,52 \%$ of the participants agreed that the exercises have clear instructions that explain how every exercises can be done, while $16 \%$ of the respondents disagreed with this statement (Item 16). $64 \%$ of the study samples agreed that the exercises tasks move from simple to complex (Item 17). About $40 \%$ of the teachers believed that the textbook's activities incorporated both individual paired and group work, while $28 \%$ of respondent disagreed with this item (Item 18). In the last case of this section, $52 \%$ of the teachers were satisfied with the statement that the textbook provides models for final achievement tests (Item 19).

Table 5. The Results of Checklist from the Social Cultural Context

\begin{tabular}{llllllll}
\cline { 2 - 7 } & Textbook evaluation scales & 0 & & 1 & & 2 & \\
\cline { 2 - 5 } Social Cultural Context & $\mathrm{N}$ & $\%$ & $\mathrm{~N}$ & $\%$ & $\mathrm{~N}$ & $\%$ \\
& 2 & 8 & 2 & 8 & 21 & 84 \\
Item 20 & 13 & 52 & 10 & 40 & 2 & 8 \\
Item 21 & 17 & 68 & 6 & 24 & 2 & 8 \\
\hline
\end{tabular}

$0=$ Poor; $1=$ Satisfactory; $2=$ Good

For the first item in social and cultural context, majority of the participants stated their agreement with the statement that the book is free from stereotypical images and information (Item 20). As indicated in table 5, 52\% of the teachers disagreed with the statement that the content presents different cultures, while $40 \%$ of them are satisfied with this item (Item 21).68\% of the respondents believed that the content doesn't discuss some well-known characters from different areas of the world, while $8 \%$ agreed this issue (Item 22).

\subsection{Revisiting the Forth Research Question}

The forth research question was" Is Vision2 appropriate for Iranian high school students in terms of language skills?" The descriptive statistics related to language skills are presented in Table 6.

Table 6. The Results of Checklist from the Language Skills

\begin{tabular}{lll|ll|ll}
\hline Textbook evaluation scales & 0 & & 1 & & 2 & \\
\hline Listening & $\mathrm{N}$ & $\%$ & $\mathrm{~N}$ & $\%$ & $\mathrm{~N}$ & $\%$ \\
Item 23 & 8 & 32 & 1 & 4 & 16 & 64 \\
Item 24 & 17 & 68 & 6 & 24 & 2 & 8 \\
Speaking & $\mathrm{N}$ & $\%$ & $\mathrm{~N}$ & $\%$ & $\mathrm{~N}$ & $\%$ \\
Item 25 & 1 & 4 & 10 & 40 & 14 & 56 \\
Item 26 & 13 & 52 & 6 & 24 & 6 & 24 \\
Reading & $\mathrm{N}$ & $\%$ & $\mathrm{~N}$ & $\%$ & $\mathrm{~N}$ & $\%$ \\
Item 27 & 14 & 56 & 5 & 20 & 6 & 24 \\
Item 28 & 2 & 8 & 3 & 12 & 20 & 80 \\
Writing & $\mathrm{N}$ & $\%$ & $\mathrm{~N}$ & $\%$ & $\mathrm{~N}$ & $\%$ \\
Item 29 & 16 & 64 & 2 & 8 & 7 & 28 \\
Item 30 & 4 & 16 & 19 & 76 & 2 & 8 \\
\hline
\end{tabular}




\begin{tabular}{lll|ll|ll}
\hline Item 31 & 5 & 20 & 5 & 20 & 15 & 60 \\
Vocabulary & $\mathrm{N}$ & $\%$ & $\mathrm{~N}$ & $\%$ & $\mathrm{~N}$ & $\%$ \\
Item 32 & 18 & 72 & 4 & 16 & 3 & 12 \\
Item 33 34 & 6 & 24 & 17 & 68 & 2 & 8 \\
Item 34 & 12 & 48 & 11 & 44 & 2 & 8 \\
Item 35 & 22 & 88 & 1 & 4 & 2 & 8 \\
Grammar & $\mathrm{N}$ & $\%$ & $\mathrm{~N}$ & $\%$ & $\mathrm{~N}$ & $\%$ \\
Item 36 & 18 & 72 & 4 & 16 & 3 & 12 \\
Item 37 & 3 & 12 & 3 & 12 & 19 & 76 \\
Item 38 & 16 & 64 & 7 & 28 & 2 & 8 \\
Item 39 & 6 & 24 & 5 & 20 & 14 & 56 \\
Item 40 & 2 & 8 & 3 & 12 & 20 & 80 \\
Pronunciation & $\mathrm{N}$ & $\%$ & $\mathrm{~N}$ & $\%$ & $\mathrm{~N}$ & $\%$ \\
Item 41 & 6 & 24 & 13 & 52 & 6 & 24 \\
Item 42 & 7 & 28 & 16 & 64 & 2 & 8 \\
\hline
\end{tabular}

$0=$ Poor; $1=$ Satisfactory; $2=\overline{=\text { Good }}$

As it was estimated, the first item in this domain confirmed positively by $64 \%$ of teachers, While $32 \%$ rejected (Item 23). Around $68 \%$ of teachers gave negative response to the second item which is about exposing the students to the voice and pronunciation of the native speakers of English (Item 24). Nearly all teachers agreed that activities are developed to encourage student-student and student-teacher oral communication (Item 25). 52\% of the participants stated that there isn't sufficient material for spoken English, while the rest responded this item in positive way (Item26). As indicated in table $6,56 \%$ of teachers believed that most of reading passages are not upto-date, interesting and meaningful (Item27). The second item in reading part is about appropriateness of reading texts length confirmed positively by $80 \%$ of teachers (Item 28). $64 \%$ of the participants did not support the first item in writing domain, but $28 \%$ of teachers agreed the statement that some of writing tasks are easy for most of the students and the rest $8 \%$ declared their satisfaction with this matter (Item 29 ). It is obvious that $76 \% 0$ f teachers expressed their satisfaction with the statement that writing in textbook are guided and controlled. However, $16 \%$ of them disagreed with this issue (Item30). 60\% indicate that writing activities are suitable in in terms of length, degree of accuracy, and amount of guidance (Item31). As shown in table 6, most of the teachers dis agreed the first item related to vocabulary that asks about appropriateness of the load (number of new words in each lesson) to the linguistic level of students (Item 32). While around 68\% of the participants were satisfied that the exercises for vocabulary are rich and adequate, $24 \%$ of the respondents expressed their disagreement (Item 33). $48 \%$ believed there isn't specific method for teach new vocabulary (Item 34). The great number of disagreement refers to the statement that the sentences and examples use the words that are known by learners, teachers also believe in lack of a glossary and vocabulary list at the end of the book (Item 35). The first item in grammar regarding the appropriateness of time allotted for teaching the material confirmed negatively by $72 \%$ of teachers, while $12 \%$ agreed and the rest 16\% were satisfied with this issue (Item 36). Most of teachers declared their agreement and satisfaction on statement that the grammar lessons are often derived from listening and reading passages (Item 37). It is obvious that $64 \%$ of teachers believed that grammar examples are not appropriate and interesting to the student's level (Item38).

This investigation showed that $56 \%$ of the participants agreed with easy and brief examples of grammar points and $24 \%$ rejected this matter (Item 39). The last item in the grammar part is about designing the structures in a way to be taught inductively confirmed positively by $80 \%$ of teachers (Item 40 ). As it is shown in table $6,52 \%$ stated that pronunciation is easy to be learnt. However, $24 \%$ of teachers denied this matter. (Item 41 ).

In the last case of this section, more than half of teachers stated their satisfactory with the last item, while $28 \%$ rejected this issue (Item 42).

\section{Discussions}

The result of analysis revealed that teachers perception about "Physical and Utilitarian Attributes" were positive in general. Although teachers believed that outside cover is not informative and attractive, they stated their agreement in other aspects related to these criteria. Participants of the study pointed out that adding title page, impact page and Get Ready part are good ideas for warming up. The results revealed that most of teachers felt negative about the textbook in term of subject and content. A great majority of teachers stated the book doesn't contain fun elements; they believed the subject and content of "Vision2" is not interesting, challenging and 
motivating. Teachers think the textbook did not appeal to students' interest. The quantitative data analyses indicated that teacher perceptions about the activities and exercises of the textbook were positive in general. Teachers emphasized that due to the vocabulary load in the reading passages, the students had great difficulty in comprehending the reading texts and doing the related tasks and activities. Teachers believed the lack of vocabulary list in each lesson or even more at the end of the book makes students confused; because most of students think the words that they should learn in each lesson is limited to "New Words and Expression "part of the book. The results also revealed that the particular textbook was good in the presentation of grammar.

The positive points are as follows:

1. The activities introduce the main principle of CLT.

2. The instructions are clear for the students.

3. The book is finely continuing the goals of "Vision1".

4. The artwork in the textbook is helpful for students to understand the lesson.

5. Teachers' guide is good for teachers to be familiar with the right ways of teaching the book.

The negative points are listed below:

1. The outside cover of book is not informative and attractive.

2. There is not balance between four skills.

3. The activities don't enable the students to use English outside the classroom.

4. The topics are not interesting.

5. The recordings are not clear and understandable for students.

6. The book is limited to three long lessons, which makes the book boring for the learners.

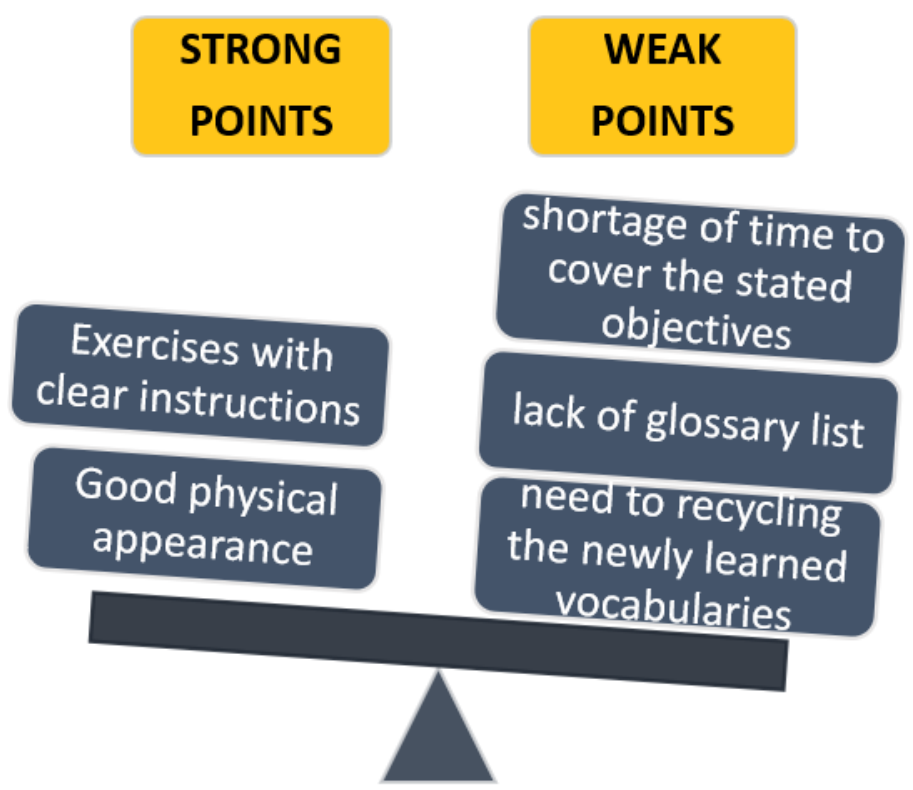

Figure 1. The positive and negative points based on textbook evaluation

\subsection{Pedagogical Implications of the Study}

In the light of the findings of the study, the researcher presents the following implications:

\subsection{Implications for Teachers}

1- Teachers should develop the teaching aids so as to be able to deal with the individual differences among students.

2- They have to be trained to employ modern technology such as computers and internet.

3- Teachers ought to provide students with additional writing texts so that they can express themselves through writing freely about their desires, needs, feelings, ... etc. 


\section{References}

Mohamed, A. W. (2013). Developing an English Language Textbook Evaluative Checklist. IOSR Journal of Research \& Method in Education (IOSR-JRME), 1(3) (Mar. - Apr. 2013), 55-70. e-ISSN: 2320-7388, p-ISSN: 2320-737X

Ahour, T., Towhidiyan, B., \& Saeidi, M. (2014). The evaluation of "English Textbook 2" taught in Iranian high schools from teachers' perspectives. English Language Teaching, $7(3), 150$. https://doi.org/10.5539/elt.v7n3p150

Amini, M., \& Birjandi, P. (2012). Gender bias in the Iranian high school EFL textbooks. ELT, 5(2), 134-147. https://doi.org/10.5539/ells.v1n2p25/

Ansary, H., \& Babaii, E. (2002). Universal characteristics of EFL/ESL textbook: step towards systematic textbook evaluation. The Internet TESL Journal, 2, 1-8.

Byrd, P. (2001). Textbooks: Evaluation for selection and analysis for implementation, in M. Celce-Murcia (ed.). Teaching English as a Second or Foreign Language:Boston. Heinle and Heinle.

Cunningsworth, A. (1984). Evaluating and Selecting EFL Teaching Materials. London: Heinemann.

Dahmardeh, M. (2009). Communicative textbooks: English language textbooks in Iranian secondary school. Linguistik Online, 4(09), 45-61. Retrieved from http://www.linguistik- online.com/40_09/dahmardeh.pdf

Hosseini, F. A., Pishghadam, R., \& Heidarian, Z. (2011). Gender delineation in high school and pre-university ELT textbooks: A criterion-oriented approach to text analysis. The Iranian EFL Journal, 7 (3), 32-47. Retrieved from http://www.iranian-efl-journal.com/

Hutchinson, T. (1987). What is underneath? An interactive view of the materials evaluation, in Sheldon, L. E. (ed.). ELT Textbooks and Materials: Problems in Evaluation and Development. Oxford: Modern English Publications, 37-44.

Jahangard, A. (2008). The evaluation of the EFL materials taught at Iranian public high schools. Asian EFL Journal, 1, 130-150. Retrieved from http://www.asian-efl-journal.com/

Jolly, D., \& Bolitho, R. (1998). A framework for materials writing, in Tomlinson, B.(ed.). Materials Development in Language Teaching. Cambridge: Cambridge University Press, 90-115.

Littlejohn, A. (2011). The analysis of language teaching materials: Inside the Trojan Horse. In B. Tomlinson (Ed.), Materials development in language teaching (pp. 179-211). Cambridge: Cambridge University Press.

Litz, D. R. A. (2001). Textbook evaluation and ELT management: A South Korean case study. Retrieved July, 2015, from http://www.pdfgeni.com

Litz, R. A. D. (2002). Textbook evaluation and ELT management: A South Korean Case Study. Asian EFL Journal, 5-53.

McGrath, I. (2013). Teaching Materials and the Roles of EFL/ESL Teachers. London: Bloomsbury.

Moghtadi, L. (2014). Iranian high school EFL textbooks: Why they should be modified.International Journal of Language Learning and Applied Linguistics World (IJLLALW), 5(2), 53-69.

Nevo, D. (1977). A model for Utilization of Formative Evaluation in the Process of Developing Instructional Materials. PLETA Journal, 14(2).

Nunan, D. (1988). Principles for designing language teachinmaterials. Guidelines, 10, 1-24.

Razmjoo, S. A. (2007). High schools or private institutes textbooks? Which fulfill communicative language teaching principles in the Iranian context? Asian EFL Journal, 9(4), 126-140. Retrieved from http://www.asian-efl-journal.com/

Riasati, M. J., \& Zare, P. (2010). EFL teachers' perspectives on "New Interchange”. Studies in Literature and Language, 1(8), 54-60.

Riazi, A. M., \& Mosalanejad, N. (2010). Evaluation of learning objectives in Iranian High- School and PreUniversity English textbooks using Bloom's Taxonomy. The Internet TESL Journal, 13(4), 1-16. Retrieved from http://www.tesl-ej.org/wordpress/issues/volume13/ej52/

Richards, C. J. (1994). The Context of Language Teaching. Cambridge: Cambridge University Press.

Rimani, N. F., \& Soleimani, F. (2012). The manifestation of culture in Iranian and Turkish high school English 
textbooks. Academic Research International, 2(3), 646-656. Retrieved from http://www.savap.org.pk/journals/ARInt./Vol.2(3)/2012(2.3-78).pdf

Sheldon, L. (1988). Evaluating ELT textbooks and materials. ELT Journal, 42(4), 237-46. https://doi.org/10.1093/elt/42.4.237

Tomlinson, B. (1998). Introduction, in Tomlinson, B. (ed.). Materials Development in Language Teaching. Cambridge University Press, pp.1-24.

Zohrabi, M., Sabouri, H., \& Kheradmand, M. (2014). Comparative study of Interchange1 and English book1 of Iranian high schools. Education International Journal of English, 3(2), 95-104.

\section{Appendix}

\section{Textbook Evaluation Form}

Dear colleagues, please provide the following information.

1) Gender: male..... female.....

2) Teaching experience: -------- years

This study was conducted to find out the overall attitudes of high school teachers about evaluation of "Vision 2". According to your personal idea, please rate the following items related to different features of the English textbook.

Please choose one of the choices for each item.

Please Note: Poor $=0$ Satisfactory $=1$ Good $=2$

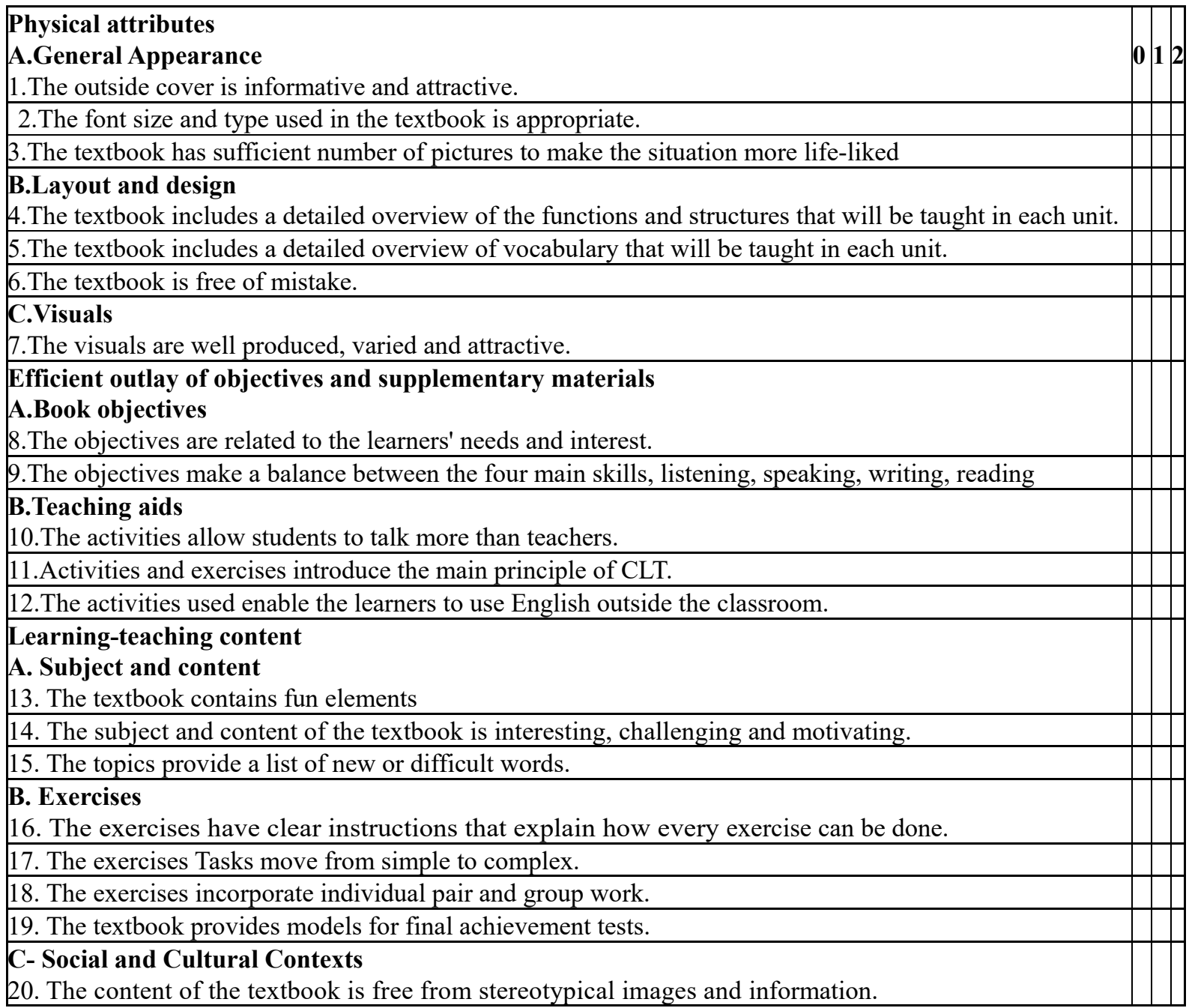


21. The content presents different cultures.

22. The content discusses some well -known characters from different areas of the world.

\section{Language Skills}

\section{A. Listening}

23. The textbook has appropriate listening tasks with well-defined goals.

24. The cassettes expose the students to the voices and pronunciation of the native speakers of English.

\section{B. Speaking}

25. Activities are developed to encourage student-student and

student-teacher oral communication.

26. There is sufficient material for spoken English (e.g. dialogues, role-plays, etc.) that help to deemphasize teacher's talk.

\section{Reading}

27. Many of the reading passages are up-to-date, interesting and meaningful

C. Reading

27. Many of the reading passages are up-to-date, interesting and meaningful

28. The Length of the reading texts is appropriate.

\section{Writing}

29. Some writings are easy for most of the students to deal with

30. Writings in the textbook are guided and controlled.

31. Writing activities are suitable in terms of length, degree of accuracy, and amount of guidance.

\section{E. Vocabulary}

32. The load (number of new words in each lesson) is appropriate to the linguistic level of students.

33. The exercises for vocabulary are rich and adequate.

34. There is specific method to teach new vocabulary.

35. The sentences and examples use words that are known by learners.

\section{F. Grammar}

36. The time allotted for teaching the material is sufficient.

37.Grammar lessons are often derived from the listening and reading passages.

38. The grammar examples are appropriate and interesting to the students' level.

39. The grammar points are presented with brief and easy examples and explanations.

40.Structures are designed to be taught inductively.

\section{G. Pronunciation}

41. It is easy to be learnt.

42. There are cassettes/CDs for pronunciation practice.

\section{Copyrights}

Copyright for this article is retained by the author(s), with first publication rights granted to the journal.

This is an open-access article distributed under the terms and conditions of the Creative Commons Attribution

license (http://creativecommons.org/licenses/by/4.0/). 